ORIGINAL ARTICLE

\title{
Physiological characteristics of top level off-road motorcyclists
}

\author{
A W Gobbi, R A Francisco, B Tuy, R S Kvitne
}

Br J Sports Med 2005;39:927-931. doi: 10.1136/bjsm.2005.018291

See end of article for authors' affiliations .....................

Correspondence to: Alberto W Gobbi, Orthopaedic Arthroscopic Surgery International, Via Amadeo G.A., 24, 20133 Milan, Italy; sportmd@tin.it

Accepted 12 April 2005

\begin{abstract}
Objectives: The study aims to analyse the physiological characteristics of top level off-road motocross, enduro, and desert rally motorcyclists to facilitate the design of a specific training program.

Methods: Twenty seven off-road top level riders participated in this study which measured anthropometric data, maximum aerobic power with incremental tests of both arms and legs, isokinetic dynamometry of the knee and elbow, handgrip strength, heart rate, and blood lactate concentrations during competition.

Results: The physical demands of the various races appear to influence the development of distinct musculoskeletal characteristics, as well as aerobic and anaerobic metabolism. Motocross riders have more muscle mass, higher isokinetic handgrip strength, and greater aerobic power than enduro and desert rally riders. However, there are no significant anthropometric and physiological differences between desert rally and enduro riders. Desert rally riders tend to be overweight with maximum aerobic power similar to that of healthy individuals. The mechanical characteristics of the motorcycle and the technical and tactical skills of the riders seem to be more important for race success than the metabolic capabilities of the rider. Conclusions: Desert rally and enduro riders present similar anthropometric and physiological characteristics. Both have a maximum aerobic power similar to that of healthy normal individuals, although desert rally riders tend to be overweight. Motocross riders on the other hand, have more muscle mass, more strength, and greater aerobic power. The differences observed suggest the need for a specific training program to address the requirements of different riders to reduce the possibility of injury.
\end{abstract}

$\mathrm{T}$ echnical skills are considered to be more important than physiological characteristics in motor sports. Off-road motorcycling is one of the most popular leisure activities and is practiced by millions of people throughout the world. Competitive races are organised at local, national, and international level. The world championship is considered to be the most prestigious competition and consists of several races during the season.

As competitive off-road motorcycling is inherently dangerous, sufficient training is necessary to reduce the possibility of injury. ${ }^{1}$ However, despite the popularity and danger of motorcycling, few studies have been carried out to assess the physiological characteristics of motorcycle riders.

The purpose of this study was to analyse the physiological characteristics of top level riders participating in three different types of off-road motorcycling (motocross, enduro, and desert rally) to facilitate the development of a specific training program.

\section{Characteristics of off-road motorcycling}

Motocross is one of the world's most popular sports. It began in the early 20th century in Great Britain and was named after the first off-road cross-country races. Motocross is a high speed competition that takes place on a rather uneven $2 \mathrm{~km}$ circuit over natural terrain with dirt, mud, sharp turns, and steep hills that allow the rider to perform jumps which can reach $20 \mathrm{~m}$ in length and $5 \mathrm{~m}$ in height. Up to 40 riders participate in each race; they are all lined up at the start and drive along the circuit as fast as possible for a fixed time of 30-40 min, according to different categories determined by the engine size of the motorcycles. The competition consists of two "matches" with a short break between them.

Enduro races take place over country roads, mule tracks, and public streets under ordinary traffic rules. These routes are unknown to the riders and they may encounter unexpected obstacles and unmarked roads. The distances between several checkpoints must be covered within a fixed time (that is, within a fixed average speed), stressing endurance rather than speed. Along the route there are sometimes trials $4-10 \mathrm{~km}$ long that must be covered as fast as possible. The competition usually lasts $6-8 \mathrm{~h}$ and the final result is calculated as the sum of the times of the trials and the penalties acquired due to differences between the fixed required time and the actual time spent covering the route.

Desert rallies are races that last for several days (up to 20) and are thousands of kilometres long (the Paris-Dakar race has reached $14000 \mathrm{~km}$ ). During the rally, the riders must find their way with the help of a road book and GPS system given at the start of the competition. As desert areas and wild, uninhabited places are often crossed, unexpected trouble whether from the motorcycle or other causes could have tragic consequences. The characteristics of the motorcycles used in the different types of racing are given in table 1.

\section{METHODS}

Twenty seven off-road, top level, male motorcyclists with international race experience were examined in this study after giving written consent. They consisted of three distinct groups of riders; nine motocross, nine enduro, and nine desert rally riders. Ten male distance runners were recruited as controls.

\section{Anthropometry}

The percentage of body fat was assessed by an anthropometric method. The body mass index (BMI) was calculated from the formula: [mass $(\mathrm{kg}) \times$ height $(\mathrm{m})]^{2}$.

Abbreviations: $B M I$, body mass index; $E E$, elbow extensors; $E F$, elbow flexors; KE, knee extensors; KF, knee flexors; MPT, maximum peak torque; $\mathrm{Vo}_{2 \text { max }}$, maximum aerobic power 
Table 1 Mechanical characteristics of the motorcycles used by the riders

\begin{tabular}{lcrc}
\hline & Motocross & Enduro & Desert rally \\
\hline Cubic capacity (cc) & 250 & 250 & 900 \\
Weight (kg) & 98 & 103 & 210 \\
Power (hp) & 50 & 46 & 80 \\
$\begin{array}{l}\text { Maximum front wheel } \\
\text { suspension range (mm) }\end{array}$ & 300 & 285 & 280 \\
$\begin{array}{l}\text { Maximum back wheel } \\
\text { suspension range (mm) }\end{array}$ & 320 & 320 & 250 \\
$\begin{array}{l}\text { Maximum front wheel } \\
\text { suspension force (N) }\end{array}$ & 8000 & 6000 & 7000 \\
$\begin{array}{l}\text { Maximum back wheel } \\
\text { suspension force (N) }\end{array}$ & 12000 & 10000 & 10000 \\
\hline
\end{tabular}

Power at the wheel was measured in the laboratory as were the range and force of the suspensions using position and force transducers. Data were provided by the manufacturers. Note the effective power at the wheel during laboratory trials and the maximum load the suspension can reach (10-15 times the body mass).

\section{Maximum aerobic power}

The maximum aerobic power $\left(\mathrm{Vo}_{2 \max }\right)$ was measured using both arm and leg incremental tests. The leg test was carried out using a cycloergometer (Monark, Varberg, Sweden) starting at $60 \mathrm{~W}$ with increments of $30 \mathrm{~W}$ every 3 min until exhaustion. On a separate day, the arm test was carried out with arm cycling ergometer (Monark Rehab Trainer 881). The starting power was $19 \mathrm{~W}$ with increments of $19 \mathrm{~W}$ every 3 min until exhaustion.

For both tests, the $\mathrm{Vo}_{2 \max }$ was measured by using the open circuit method. The expired air was collected at the last minute of the test in a Douglas bag and the gas concentrations were determined using a paramagnetic oxygen analyser (Taylor, Milan, Italy) and an infrared carbon dioxide analyser (Leybold-Heraeus, Hanau, Germany), frequently calibrated against known gas mixtures (fig 1 ). The gas volume was measured by a dry gas meter (WE Collins, Braintree, MA).

\section{Isokinetic test}

Maximum peak torque (MPT) of the knee extensors (KE) and flexors (KF) and elbow extensors (EE) and flexors (EF) was measured using an isokinetic dynamometer (Cybex, Lumex, Ronkonkoma, NY). Subjects were tested on a different day than the $\mathrm{VO}_{2 \max }$ tests.

$\mathrm{KE}$ and KF were measured in a sitting position with the axis of rotation of the lever arm of the dynamometer aligned with the axis of rotation of the knee joint. After a short warm up, the subject was asked to perform knee extension and flexion at maximum speed and strength. Four repetitions were performed at angular speeds of $0^{\circ} \mathrm{s}^{-1}$ (isometric) and $60^{\circ} \mathrm{s}^{-1}$. Both limbs were tested in random order.

The same speeds were used when assessing the MPT of EE and EF. The isometric test was performed with the elbow joint at $90^{\circ}$ flexion. Care was taken to align the axis of rotation of the elbow joint with that of the lever arm of the dynamometer. The higher value of MPT of each speed was chosen for calculation.

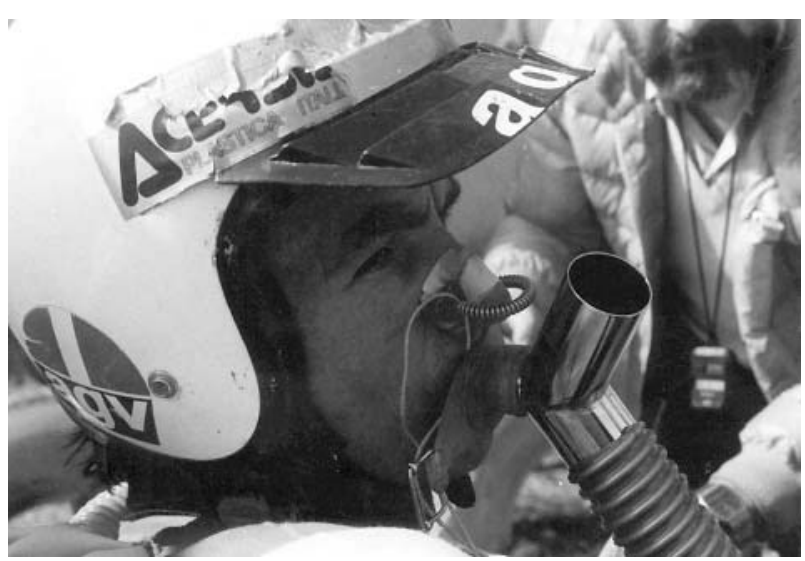

Figure 1 Maximum aerobic power $\left(\mathrm{Vo}_{2 \max }\right)$ measurement obtained by analysing expired air with an oxygen and carbon dioxide analyser. (This photograph is reproduced with the permission of the subject.)

\section{Handgrip}

Maximum isometric force was measured with a mechanical handgrip dynamometer (Lafayette Instruments, Paris, France). The subjects sat with the elbow joint maintained at $90^{\circ}$ flexion. A clear command was given to squeeze the handle of the dynamometer as hard as possible and to hold it in place for $5 \mathrm{~s}$. Three attempts were made with both the right and left hand. The highest reading was recorded and a minimum of 2 min was allowed between tests.

\section{Measurements during competition}

Heart rate was recorded during international competition with a heart rate recorder (Sport Tester PE 3000; Polar Electro, Kempele, Finland). Blood lactate concentration was determined within $2 \mathrm{~min}$ of the end of a race by taking a microsample of arterialised blood from the ear lobe and immediately analysing it with a lactate analyser (YSI, Yellow Springs, $\mathrm{OH}){ }^{2}$

\section{Statistics}

Difference between groups were assessed by one way analysis of variance. Differences between dominant and non-dominant limbs were assessed by paired Student's $t$ tests. The values were considered to be significant at the $\mathrm{p}<0.05$ level.

\section{RESULTS}

The anthropometric characteristics of the riders are shown in table 2 . The BMI of desert rally riders was significantly higher $(p<0.005)$ than that of the other groups. However, the percentage of body fat was similar in all three groups of motorcyclists. $\mathrm{Vo}_{2 \max }$ measured with the leg test was significantly higher in the motocross compared to the enduro $(\mathrm{p}<0.02)$ and the desert rally $(\mathrm{p}<0.001)$ riders when normalised for body weight (table 3 ). $\mathrm{Vo}_{2 \max }$ measured with the arm test was significantly higher in the motocross riders when expressed both in absolute $(\mathrm{p}<0.02)$ and normalised $(\mathrm{p}<0.001)$ values. The values of $\mathrm{Vo}_{2 \max }$ were always lower in the arm test compared to the leg test $(\mathrm{p}<0.005)$.

Table 2 Anthropometric characteristics of the off-road motorcyclists

\begin{tabular}{lcllll}
\hline & $\mathbf{n}$ & Age (years) & Body mass $(\mathbf{k g})$ & Height $(\mathbf{c m})$ & Fat $(\%)$ \\
\hline Motocross & 7 & $23 \pm 4$ & $74.7 \pm 8.1$ & $177 \pm 9$ & $13.3 \pm 3.1$ \\
Enduro & 10 & $29 \pm 6$ & $75.4 \pm 9.0$ & $176 \pm 7$ & $23.7 \pm 0.6$ \\
Desert rally & 10 & $32 \pm 3$ & $79.2 \pm 3.4$ & $176 \pm 3$ & $12.6 \pm 3.7$ \\
Controls & 5 & $25 \pm 3$ & $76.8 \pm 6.2$ & $185 \pm 5$ & $15.1 \pm 3.4$ \\
\hline
\end{tabular}

Values are mean $\pm S D$. 
Table 3 Maximum aerobic power with arm and leg tests

\begin{tabular}{|c|c|c|c|c|}
\hline & \multicolumn{2}{|l|}{ Arm } & \multicolumn{2}{|l|}{ Leg } \\
\hline & $1 \min ^{-1}$ & $\mathrm{ml} \mathrm{kg}{ }^{-1} \min ^{-1}$ & $1 \min ^{-1}$ & $\mathrm{ml} \mathrm{kg}{ }^{-1} \min ^{-1}$ \\
\hline $\begin{array}{l}\text { Motocross } \\
\text { Enduro } \\
\text { Desert rally } \\
\text { Controls }\end{array}$ & $\begin{array}{l}3.55 \pm 0.70 \\
2.82 \pm 0.41 \\
2.65 \pm 0.50 \\
2.45 \pm 0.25\end{array}$ & $\begin{array}{l}47.7 \pm 8.9 \\
36.3 \pm 7.9 \\
33.5 \pm 6.7 \\
31.9 \pm 3.7\end{array}$ & $\begin{array}{l}4.28 \pm 0.56 \\
3.86 \pm 0.45 \\
3.89 \pm 0.35 \\
3.22 \pm 0.35\end{array}$ & $\begin{array}{l}57.5 \pm 6.7 \\
49.5 \pm 7.3 \\
49.1 \pm 3.7 \\
41.9 \pm 5.4\end{array}$ \\
\hline
\end{tabular}

No differences were found between the left and the right limbs in the three groups of riders for both isometric and isokinetic tests. The motocross riders showed a significantly higher isometric force for the KE and KF than the control subjects $(p<0.001)$. The control subjects showed significantly lower force in all tests of the upper limbs carried out with the isokinetic dynamometer (all $\mathrm{p}<0.001$; table 4 ). In isometric conditions, the MPT of the left KE was significantly lower in the desert rally compared to the enduro $(\mathrm{p}<0.01)$ and motocross $(\mathrm{p}<0.01)$ riders. Desert rally riders also showed significantly lower isometric force compared to enduro in the right $\mathrm{KF}(\mathrm{p}<0.003)$ and motocross riders in the left $\mathrm{KF}$ $(p<0.05)$, right $E E(p<0.01)$, right $E F(p<0.01)$, and left $E F$ $(p<0.002)$. Enduro riders showed significantly lower isometric force compared to motocross riders in the right $\mathrm{KF}$ $(\mathrm{p}<0.001)$ and left $\mathrm{KF}(\mathrm{p}<0.03)$. In isokinetic conditions at $60^{\circ} \mathrm{s}^{-1}$, motocross riders were significantly stronger than desert rally riders in the left $\mathrm{KF}(\mathrm{p}<0.05)$ and enduro riders in the left EF $(p<0.05)$. The three groups of riders showed similar force values in the handgrip tests (table 5 ). The force was always higher than that of the control subjects ( 10 distance runners) in both limbs $(\mathrm{p}<0.001)$. Only the motocross riders showed a higher force in the left handgrip $(\mathrm{p}<0.05)$.

\section{DISCUSSION}

Exercise physiology has always been dedicated to the study of the different forms of human locomotion (for example, walking, running, swimming, cycling, cross-country skiing), but little effort has been devoted to the study of the characteristics of competitive off-road motorcycle riders. Indeed, the physiological characteristics of the rider often are not considered to contribute to overall performance in competition.

In our study, the weight of the motocross and enduro riders was found to be in the higher range of normal values, while desert rally riders tended to be overweight. In motor sports, being overweight is unfavourable because it overloads the bike as well as providing extra mass that must be accelerated (and decelerated during braking). Therefore, the heavier rider requires more muscular force for optimal control of his motorcycle. This situation is common to other extreme sports such as high altitude alpine sports and ultra-long distance marathons. For participants in these sports, a higher percentage of adipose tissue might be considered an energy reserve and consequently a positive factor for performance. ${ }^{3}$

As far as motocross is concerned, the duration of the competition and the frequent changes of direction and speed due to the characteristics of the circuit require constant involvement of all the muscle groups in the body. ${ }^{4-7}$ Therefore, both aerobic and lactic acid metabolism is involved. Maximum aerobic power was higher in the motocross riders compared both to sedentary individuals $(\mathrm{p}<0.01)$ and to the desert rally and enduro riders $(\mathrm{p}<0.001)$.

The highest oxygen consumption achieved during arm exercise varies between 64 and $80 \%$ of leg $\mathrm{Vo}_{2 \max } \cdot{ }^{8}$ This difference is probably due to the relatively small muscle mass of the upper body involved in arm ergometry. In the present study, a similar difference was also found: the arm $\mathrm{Vo}_{2 \max }$ was $83 \%, 73 \%$, and $69 \%$ of the $\mathrm{Vo}_{2 \max }$ in motocross, enduro, and desert rally riders, respectively. The lower maximum aerobic power of the enduro and desert rally riders may be due the lesser involvement of the upper arms compared to the motocross riders.

A peculiar characteristic of motocross riders is their higher aerobic power. Our observations in 23 motocross riders with international competition experience revealed that in this group of sportsmen, arm $\mathrm{Vo}_{2 \max }$ was significantly lower $\left(2.78 \pm 0.51 \mathrm{l} \mathrm{min} \mathrm{m}^{-1}, \mathrm{p}<0.001\right)$ compared to top level motocross riders. The relationship between arm and leg $\mathrm{Vo}_{2 \text { max }}$ confirmed that these riders have less power and are less able to recruit other muscle groups with static functions during arm exercises.

Table 4 Maximum peak torque $(\mathrm{Nm})$ of knee extensors and flexors and elbow extensors and flexors of both right and left limbs

\begin{tabular}{|c|c|c|c|c|c|c|c|c|}
\hline & \multicolumn{4}{|l|}{ Isometric } & \multicolumn{4}{|c|}{$60 \operatorname{deg~s}^{-1}$} \\
\hline & \multicolumn{2}{|l|}{ KE } & \multicolumn{2}{|l|}{ KF } & \multicolumn{2}{|l|}{ KE } & \multicolumn{2}{|l|}{ KF } \\
\hline & $R$ & $\mathbf{L}$ & $R$ & $L$ & $\mathbf{R}$ & L & $\mathbf{R}$ & L \\
\hline $\begin{array}{l}\text { Motocross } \\
\text { Enduro } \\
\text { Desert rally } \\
\text { Controls }\end{array}$ & $\begin{array}{l}277 \pm 34 \\
251 \pm 47 \\
236 \pm 64 \\
224 \pm 51\end{array}$ & $\begin{array}{l}266 \pm 43 \\
253 \pm 46 \\
221 \pm 51 \\
220 \pm 50\end{array}$ & $\begin{array}{l}167 \pm 26 \\
172 \pm 34 \\
185 \pm 38 \\
155 \pm 35 \\
\end{array}$ & $\begin{array}{l}146 \pm 31 \\
160 \pm 36 \\
161 \pm 57 \\
151 \pm 40 \\
\end{array}$ & $\begin{array}{l}222 \pm 24 \\
211 \pm 42 \\
198 \pm 48 \\
185 \pm 35 \\
\end{array}$ & $\begin{array}{l}199 \pm 21 \\
203 \pm 45 \\
193 \pm 41 \\
181 \pm 38 \\
\end{array}$ & $\begin{array}{l}141 \pm 18 \\
145 \pm 26 \\
152 \pm 31 \\
133 \pm 25\end{array}$ & $\begin{array}{l}135 \pm 17 \\
145 \pm 32 \\
158 \pm 22 \\
130 \pm 25\end{array}$ \\
\hline & \multicolumn{2}{|l|}{$\mathrm{EE}$} & \multicolumn{2}{|l|}{ EF } & \multicolumn{2}{|l|}{$\mathrm{EE}$} & \multicolumn{2}{|l|}{ EF } \\
\hline & $R$ & $L$ & $R$ & L & $R$ & $\mathbf{L}$ & $R$ & $\mathbf{L}$ \\
\hline $\begin{array}{l}\text { Motocross } \\
\text { Enduro } \\
\text { Desert rally } \\
\text { Controls }\end{array}$ & $\begin{array}{c}110 \pm 31 \\
94 \pm 19 \\
83 \pm 7 \\
45 \pm 10\end{array}$ & $\begin{array}{r}107 \pm 28 \\
92 \pm 17 \\
88 \pm 12 \\
42 \pm 10\end{array}$ & $\begin{array}{l}96 \pm 12 \\
88 \pm 11 \\
83 \pm 8 \\
41 \pm 8\end{array}$ & $\begin{array}{c}100 \pm 10 \\
87 \pm 11 \\
85 \pm 7 \\
39 \pm 10\end{array}$ & $\begin{array}{l}71 \pm 16 \\
77 \pm 11 \\
73 \pm 8 \\
42 \pm 9\end{array}$ & $\begin{array}{l}75 \pm 7 \\
76 \pm 11 \\
71 \pm 8 \\
40 \pm 9\end{array}$ & $\begin{array}{l}78 \pm 13 \\
73 \pm 10 \\
77 \pm 11 \\
39 \pm 8\end{array}$ & $\begin{array}{l}81 \pm 8 \\
72 \pm 8 \\
73 \pm 8 \\
35 \pm 9\end{array}$ \\
\hline
\end{tabular}

Values are mean $\pm S D$. EE, elbow extensors; $E F$, elbow flexors; $K E$, knee extensors; $K F$, knee flexors; L, left limb; R, right limb. 
Table 5 Maximum isometric force (N) measured with the right and left handgrip tests

\begin{tabular}{llll}
\hline & Right & Left & p \\
\hline Motocross & $511 \pm 51$ & $545 \pm 61$ & $<0.05$ \\
Enduro & $506 \pm 52$ & $506 \pm 47$ & NS \\
Desert rally & $500 \pm 50$ & $499 \pm 53$ & NS \\
Controls & $469 \pm 45$ & $444 \pm 54$ & $<0.001$ \\
\hline \multirow{2}{*}{ Mean \pm SD values and statistical significance are shown. }
\end{tabular}

Handgrip strength was similar in the three groups of riders (table 5), and higher than in the control group as both hands are used during bike riding. Maughan et al reported that in untrained subjects there is a significant difference in handgrip strength between the dominant and non-dominant limb. These differences presumably reflect the greater use of the dominant arm in normal daily activities. In our control group, the difference amounted to $6 \%(\mathrm{p}<0.001)$, while it was absent in enduro and desert rally riders. However, in motocross riders, the left arm, which was the non-dominant arm in all subjects, was significantly stronger than the right arm $(+6 \%, p<0.05)$. This difference may be due to the use of the clutch lever by the left hand, which is more frequent in motocross. Muscular strength was also measured in isometric and isokinetic conditions at a low angular speed of $60^{\circ} \mathrm{s}^{-1}$ (table 4) in accordance with Mitchell et al. ${ }^{10}$ The fact that we found significant differences between the three groups of motorcyclists in all isometric conditions but in only two isokinetic movements indicates that the isometric actions of the riders are different, while the isokinetic tests seem to be less specific for detecting differences between motorcyclists.

The data of the present study also show that there are significant differences between motorcyclists and control subjects in the isometric and low speed isokinetic strengths of the upper limbs $(\mathrm{p}<0.001)$, while only motocross riders are significantly stronger than the control subjects in the lower limbs (left and right knee KE: $\mathrm{p}<0.01$ ).

Test data collected during the races also showed that the different off-road motorcyclists had different physiological characteristics. Table 6 shows the range of heart rate values during competition and the mean values of blood lactate concentrations measured at the end of the race. In motocross, the heart rate is generally higher than $80 \%$ of the maximum theoretical heart rate and is maintained at quite high levels for the duration of the race. On the other hand, in enduro and desert rally competition, the heart rate was generally lower (20-50\% of maximum heart rate) and tended to increase during the most difficult parts of the track, but only for a few minutes. Astrand and Rodhal ${ }^{11}$ reported heart rates of between 155 and 174 beats per minute (bpm) during a 510 min simulated motocross race and $180-200 \mathrm{bpm}$ in a real race over $45 \mathrm{~min}$.

Table 6 Heart rate during competition and blood lactate concentrations measured at the end of the race

\begin{tabular}{|c|c|c|c|c|}
\hline & $\begin{array}{l}\text { Time } \\
(\min )\end{array}$ & $\begin{array}{l}\text { Heart rate } \\
(\mathrm{bpm}) \text {, range }\end{array}$ & $\begin{array}{l}V o_{2 \max } \\
(\%)\end{array}$ & $\begin{array}{l}{[\mathrm{La}]_{\mathrm{b}}} \\
(\mathrm{mM})\end{array}$ \\
\hline Motocross & 30 & $180-200$ & $80-100$ & $5.3 \pm 2.1$ \\
\hline $\begin{array}{l}\text { Enduro } \\
\text { (special) }^{*}\end{array}$ & 5 & $180-195$ & $80-95$ & $3.8 \pm 1.3$ \\
\hline $\begin{array}{l}\text { Enduro } \\
\text { (transfer)t }\end{array}$ & 480 & $80-140$ & $20-30$ & $1.5 \pm 0.3$ \\
\hline Desert rally & 420 & $100-150$ & $30-50$ & $1.1 \pm 0.3$ \\
\hline
\end{tabular}

\section{What is already known on this topic}

There are numerous reports describing exercise physiology as correlated with the different forms of human locomotion, but very few concern the characteristics of competitive offroad motorcycle riders. In many instances, the physiological characteristics of the rider are not considered to contribute to the overall performance during competition.

\section{What the study adds}

By providing information about anthropometric characteristics, maximum aerobic power, handgrip strength, and other important factors including isokinetic data, vital signs, and physiochemical parameters during actual competition, a better understanding of the conditioning and preparation required for competition can be achieved, thus reducing the incidence of injuries.

Blood lactate concentrations at the ends of races show that anaerobic metabolism was different in the different riders. In motocross, blood lactate concentrations were significantly higher than in enduro or desert rally races $(p<0.01)$. Astrand and Rodhal ${ }^{11}$ also reported blood lactate levels of between 5 and $8 \mathrm{mM}$ in a motocross race, while blood lactate levels were more variable $(2-12 \mathrm{mM})$ in a simulated event. According to Relly and Secher, ${ }^{12}$ motocross is a sport with mixed aerobic-anaerobic demands, while enduro and desert rally are mainly aerobic. Lactate accumulation is related to the fatigue that typically occurs with intensive exercise. ${ }^{13}$ Fatigue in motocross is due mainly to the static involvement of several muscle groups together with the jumping and landing movements. This fatigue produces a decrease in the muscular force necessary to oppose the negative and positive acceleration of the engine during the race and is one of the human factors that may limit performance in motor sports and must, therefore, be considered during training.

\section{CONCLUSION}

Desert rally and enduro riders have similar anthropometric and physiological characteristics. Although desert rally riders tend to be overweight, both have a maximum aerobic power similar to that of healthy normal individuals. Motocross riders, on the other hand, have more muscle mass, higher strength, and greater aerobic power, physical attributes which enhance their ability to effectively maximise the mechanical and technical capabilities of modern motorcycles. As these motorcycling sports require the active involvement of the entire musculoskeletal system with aerobic metabolism maintained at a level slightly above the anaerobic threshold, determination of the differences in the physical morphology of riders involved becomes more important to facilitate the design of a well structured specific training program geared towards improving the rider's ability to withstand the rigours of competition.

\section{Authors' affiliations}

A W Gobbi, R A Francisco, B Tuy, Orthopaedic Arthroscopic Surgery International, Milan, Italy

R S Kvitne, Kerlan-Jobe Orthopedic Clinic, Inglewood, CA, USA

Competing interests: none declared

The subject shown in figure 1 agreed to his photograph being published 


\section{REFERENCES}

1 Gobbi A, Sansone V, Pedotti E. The incidence of motocross injuries. J Sports Traumatol Rel Res 1992;14:241-8.

2 Stenberg J, Astrand PO, Ekblom B, et al. Hemodynamic response to work with different muscle groups, sitting and supine. J Appl Physiol 1967;22:61-70.

3 Sloan SW, De Wier JB. Normograms for prediction of body density and total body fat from skinfolds measurement. J Appl Physiol 1970;28:221-30.

4 Bar-Or O, Zwiren LD. Maximal oxygen consumption test during arm exercise - reliability and validity. J Appl Physiol 1977;38:424-6.

5 Bouchand C, Godbout P, Mondor GC, et al. Specificity of maximal aerobic power. Eur J Appl Physiol 1979:40:85-93.

6 De Boer LB, Kallal JE, Longo MR. Upper extremity prone position exercise as aerobic capacity indicator. Arch Phys Med Rehabil 1982;63:467-71.

7 Fardy PS, Webb D, Hellerstein HK. Benefit of arm exercise in cardiac rehabilitation. Phys Sports Med 1977;5:30-41.

8 Franklin BA. Exercise testing, training and arm ergometry. Sports Med 1985:2:100-19.

9 Maughan RJ, Abel RW, Watson JS, et al. Forearm composition and muscle function in trained and untrained limbs. Clin Physiol 1986;6:389-96.

10 Mitchell JH, Haskell WL, Raven PB. Classification of sports. Med Sci Sports Exerc 1994;26(10 suppl):S242-5.

11 Astrand PO, Rodhal K. Textbook of work physiology. New York: McGrawHill, 1986.
12 Relly T, Secher N. Physiology of sports: an overview, In: Relly T, Secher N Williams C, eds. Physiology of sports. London: E\&FN Spon, 1990:465-85.

13 Kindermann W, Keul J. Lactate acidosis with different forms of sports activities. Can J Appl Sports Sci 1977;2:177-82.

\section{............ COMMENTARY}

This is a unique study focusing on the anthropometric and physiological characteristics of motocross, enduro, and desert rally motorcycle riders. Motor sports are becoming increasingly popular and such a study will contribute to the development of specific training programs for motor sports participants.

N Nakamura

Osaka University Graduate School of Medicine, Department of Orthopaedics, Osaka, Japan; n-nakamura@ort.med.osaka-u.ac.jp

\section{1 th European Forum on Quality Improvement in Health Care}

26-28 April 2006, Prague, Czech Republic

For further information please go to: www.quality.bmipg.com

Book early to benefit from a discounted delegate rate 